\title{
Cancer Care Decision Making in Multidisciplinary Meetings
}

\section{Authors}

Kevin Dew, ${ }^{1}$ Maria Stubbe,${ }^{2}$ Louise Signal, ${ }^{3}$ Jeannine Stairmand,${ }^{3}$ Elizabeth Dennett, ${ }^{4}$ Jonathan Koea, ${ }^{5}$ Andrew Simpson, ${ }^{6}$ Diana Sarfati, ${ }^{3}$ Chris Cunningham, ${ }^{7}$ Lesley Batten, ${ }^{7}$ Lis EllisonLoschmann, ${ }^{7}$ Josh Barton, ${ }^{1}$ Maureen Holdaway ${ }^{8}$.

1. Sociology and Social Policy Programme, Victoria University of Wellington, New Zealand

2. Department of Primary Care and General Practice, Wellington School of Medicine and Health Sciences, University of Otago, New Zealand

3. Cancer Control and Screening Research Group, University of Otago, New Zealand

4. Department of Surgery and Anaesthesia, Wellington School of Medicine and Health Sciences, University of Otago, New Zealand

5. Department of Surgery, North Shore Hospital, Auckland 0632, New Zealand

6. Blood and Cancer Centre, Wellington Hospital, Wellington, New Zealand

7. Research Centre for Māori Health and Development, Massey University, New Zealand

8. Te Pūmanawa Hauora, Massey University, New Zealand

\section{Corresponding author}

Kevin Dew, Sociology and Social Policy Programme, Victoria University of Wellington, PO

Box 600, Wellington 6140, New Zealand

Email: Kevin.Dew@vuw.ac.nz 


\begin{abstract}
Little research has been undertaken on the actual decision making processes in cancer care multidisciplinary meetings (MDMs). This article is based on a qualitative observational study of two regional cancer treatment centres in New Zealand. We audio recorded ten meetings where 106 patient cases were discussed. Meeting members categorized cases in varying ways, drew on a range of sources of authority, expressed different value positions and utilized a variety of strategies to justify their actions. An important dimension of authority was encountered authority - the authority a clinician had because of meeting the patient. The MDM chairperson can play an important role in making explicit the sources of authority being drawn on and the value positions of members to provide more clarity to the decision making process. Attending to issues of process, authority and values in MDMs has the potential to improve cancer care decision making and ultimately health outcomes.
\end{abstract}

Keywords:

cancer; decision making; health care, teamwork; observation; research, qualitative 
The care of cancer patients is complex and multidimensional. In recent decades multidisciplinary meetings (MDMs) have become increasingly common sites for treatment decisions to be discussed and finalized (Fleissig, Jenkins, Catt, \& Fallowfield, 2006; Saini et al., 2012). Guidelines for the care of cancer patients frequently include recommendations that patients should be reviewed in this context (National Institute for Health and Clinical Excellence, 2006, 2008; New Zealand Guidelines Group, 2011). There is clinical consensus that the MDM process is a useful one, and growing evidence that MDMs are associated with improved clinical decision making, clinical outcomes, patient experience, and the working lives of team members (Taylor et al., 2010).

The goal of MDMs is to draw on the expertise of different specialties to make evidencebased recommendations for patient management (Patkar et al., 2011). There has been some research that has investigated how decisions are made in the context of cancer care MDMs, but to date this has been based on participant interviews or observations usually of one or two cancer care MDM teams in single specialities (Haward et al., 2003; Kidger, Murdoch, Donovan, \& Blazeby, 2009; Lanceley, Savage, Menon, \& Jacobs, 2008; Prades \& Borras, 2011). Understanding how decisions are made is important because it impacts on what decisions are made.

Research in other settings has indicated the way in which particular constructions of patients are arrived at in team meetings, and moral evaluations of those constructions has been demonstrated (Crepeau, 2000). Patients can be characterized in negative ways - such as being 'demanding'. Where such representations occur teams should reflect on these representations to foster different thinking (Arber \& Gallagher, 2009; Opie, 2000). For teams to work effectively agendas have to be aligned, but participants use rhetorical strategies, including asking questions, 
in attempts to influence interprofessional interactions (Arber, 2008). White, who used membership categorization analysis in her study of child health service decision making, argued the need to examine the argumentative strategies of clinicians and others involved in the construction of particular versions of a case because moral judgements and the characterizations of patients and other relevant parties provide the warrant for the course of action taken (White, 2002).

Furthermore, medical specialists frequently base their decisions in MDMs on biomedical factors, such as the type of cancer, its extent, and medical or surgical procedures undertaken; social and other factors that might be relevant, such as family support, are only infrequently considered. There is parallel evidence that cancer care MDM processes do not encourage the input of nurses and other nonmedical staff (Kidger et al., 2009; Lamb, Brown, Nagpal, Vincent, \& Green, 2011; Lamb, Sevdalis, Mostafid, Vincent, \& Green, 2011; Lanceley et al., 2008).

Research in other settings, such as hospice care, has explored the basis for decision making, which can include seeking patient and family needs and focusing on the feelings of patients and families (Wittenberg-Lyles, 2005). Team discussions can be hindered when team members who could provide additional relevant information to the cases being discussed are not present (Demiris, Washington, Parker Oliver, \& Wittenberg-Lyles, 2008). On the other hand, doctor and nurse-led meetings might focus on the sharing of clinical information. In these teams the sharing of psychosocial information, defined by Wittenberg-Lyles as information about the patient that was not considered medically necessary, can give rise to tension in the team such as feelings of discomfort or unease (Wittenberg-Lyles, 2005). Wittenberg-Lyles illustrated this in her research when a graphic description of a patient's situation as a result of morbidity gave rise to disquiet in the meeting. 
For the research we report here we analyzed decision making in selected cancer care MDMs across a range of specialities using audio recordings of meetings. It is part of a multiple phased research programme that uses qualitative methods to explore the cancer care journey of patients and how aspects of health care delivery lead to unequal outcomes for different ethnic groups. In the New Zealand context the particular issue is significant inequalities in cancer survival between Māori (the indigenous population) and non-Māori, and evidence that comorbidity (the presence of other health problems) and service access play important roles in

this disparity (Cormack, Ratima, Robson, Brown, \& Purdie, 2005; Hill, Sarfati, Blakely, Robson, Purdie, Chen, et al., 2010; Hill, Sarfati, Blakely, Robson, Purdie, Dennett, et al., 2010).

\section{Methods}

The initial theoretical perspective that we took was ethnomethodological in orientation.

Ethnomethodology seeks to describe the methods people use when they are 'doing' social life (ten Have, 2004). A goal of this orientation is to identify the interactional work that talk does in the context in which we see it being done (Lepper, 2000). That is, in addition to the content of what is said there is some action being performed by what is being said, such as a request or a justification. Two approaches used to try to elucidate people's methods are Conversation Analysis (CA) and the analysis of Membership Category Devices.

We audio recorded ten MDMs covering four specialities (breast, lung, upper gastrointestinal and colorectal) where cancer treatment options were discussed. In total there were 106 patients discussed in meetings in two of the six regional cancer treatment centres in New Zealand. The total time recorded was 7 hours and 25 minutes. Ethical approval for this research was granted from the New Zealand Multi-region Ethics Committee. All participating 
members of the multidisciplinary meetings signed consent forms. Consent was not sought from the patients discussed in the MDMs because the data was anonymized.

Audio recordings were transcribed for content. Transcriptions were proofed against audio recordings and anonymized. Two research team members (Kevin Dew and Maria Stubbe) listened to all recordings to identify features of the meeting that were of analytic interest and to provide an overall description of the processes and activities in the team meetings. We used the conventions of CA on selected 'cases' to extend the analysis (ten Have, 1999).

CA involves an analysis of the sequential unfolding of the interactions in the meeting to identify how and what issues are 'recognized' and 'attended to' by the participants. CA assumes that all utterances perform social actions and attends to these actions by asking why this utterance is in this place at this time (Heritage \& Maynard, 2006). For this reason CA transcripts provide more detail than orthographic transcripts, including the identification of pauses, overlap in talk and changes in intonation.

CA has been drawn on previously to better understand decision making and outcomes in health care settings. For example, in exploring the ways in which cases are constructed by health professional teams in paediatric care (White, 2002) and the way doctors and parents negotiate treatment recommendations in acute care encounters (Stivers, 2006).

An initial issue for our analysis was to describe the 'activity', and to pay close attention to the details of social interaction to generate an understanding of the ordered nature of the interaction (Heritage \& Maynard, 2006). The analysis was deepened through the process of CA transcription and then through data sessions where we listened to the audio recordings while reading the transcripts, noting features of the interaction and discussing their interpretation. CA is one way of getting at an interpretation of talk: through attending to the fine details of talk and 
the talk sequences we were able to identify aspects of the social interaction that were not obvious to us on first viewing, such as instances where suggestions were not followed up and the strategies used in persuasion.

In addition we examined the Membership Category Devices at play (Stokoe, 2012). These devices refer to how the participants position the behaviour and talk of other participants and what identity categories they use when discussing patients in the meeting. Membership categorization analysis is a way of studying 'social structure-in-action' (Lepper, 2000) and we can ask why particular identities are made relevant and what are the consequences of such a categorization (Stokoe, 2012). Given our interest in ethnicity as a category we deemed membership categorization analysis to be an ideal approach.

To undertake the analysis all instances where patients were given a category within the interaction were identified. In all instances where ethnicity was given as a category these were closely examined, and all instances where extra-classificatory work was evident were also closely examined. By extra-classificatory work we are referring to situations where the common set of categories identified in the data were used with additional categories. Common categories were gender (except in the breast cancer MDMs) and age. Less common were occupation and psychosocial classifications such as 'frail', 'independent' and 'prickly' In addtion we selected cases that appeared to be straightforward for CA transcription and contrasted these with other cases where there appeared to be something different about the discussion, such as a greater use of humour, emotional expression or use of unusual categorizations. By straightforward we are referring to a common circumstance where the case was presented and a plan of action was accepted and there was no discussion beyond matters of clarification. 
Initial ideas from this preliminary analysis were taken to meetings with research team members, including clinicians, to clarify issues identified in the recordings and obtain feedback on the interpretation of the data. As the analysis progressed it became clear to us that different values and various forms of authority were being called on in patient discussions. Although we could not relate these directly to different outcomes for different social groups, because these different values and sources of authority have the potential to lead to different outcomes we attempted to systematically identify the different values at play and the different dimensions of authority being called on to justify particular action plans.

\section{Findings}

The MDMs were held weekly or fortnightly and varied in composition but typically included surgeons, medical and radiation oncologists, pathologists, radiologists and for some MDMs clinical nurse specialists. There were usually 10 to 15 participants. The meetings ranged in length from 27 to 59 minutes. The number of patients discussed at each meeting ranged from 7 to 19 . Discussion time per patient ranged from 27 seconds to 11 minutes. The shortest times are accounted for by cases that did not proceed to a full discussion, for example because the necessary information or results were not available.

What categories were made relevant varied between MDMs. Except for the breast MDMs, gender was almost always noted and age was frequently mentioned. Ethnicity, geographic location of the patient and the patient's occupation were rarely mentioned. Categorizations relating to overall physical state were infrequently used, such as a patient being "resilient", "active", "fit", or "frail". Other categorizations relating to a personality trait or psychological state were also infrequently used, such as "fraught" and "prickly". 
For different meetings the overall structure, processes and activities undertaken were shaped by the different types and sources of information referred to, and the stage at which a case was typically brought to the meeting. For example, in the breast MDMs a surgeon had typically already seen the patient and operated, but in other MDMs decisions about surgery had not yet been taken.

\section{Topics of Discussion}

Most of the MDM discussion was based on biomedical 'objective' pathological and radiological findings, and was highly tumour focused. Occasionally 'subjective' or qualitative information about the person or their social world was noted. For example, references were sometimes made to the type of person (e.g., resilient) and patient's attitude to treatment (e.g., reluctant to have radiotherapy). However, these instances were exceptions. Demographic aspects such as age and gender were more commonly mentioned. This focus on clinical issues contrasts with MDM studies in other clinical arenas, such as in Opie's study of disability, psychiatric and elderly care MDMs (Opie, 2000). In most such teams many members had met the person being discussed in the meeting. This is also the case in the palliative care situation, the focus of research by Arber, Wittenberg-Lyles and others (Arber, 2008; Wittenberg-Lyles, 2005), and in early work by Gubrium on nursing home care (Gubrium, 1980). By contrast, in the cancer care MDMs in this study it was the usual case for only one or two of the team members to have met the person. There are then two distinctly different types of meeting, one where multidisciplinary teams come together in a meeting, and one, the focus of this research, where practitioners from different disciplines come together to discuss patients in the spirit of peer review.

Structure of MDMs 
In some meetings there was an identified chairperson who did not present any cases, whereas in others the chairperson also presented cases. The interaction in the latter was more like a 'question/answer' session rather than a discussion, particularly if the chairperson had a preferred treatment plan. Some MDMs did not have a formal chairperson, in effect leaving the presenting clinician to 'chair' their own case, with other speakers mostly 'self-selecting' for turns at talk, which sometimes resulted in a degree of overtalk and informality.

Case discussions followed a predictable overall structure which typically includes the following elements:

1. Opening: identification of the patient who was to be the next subject of discussion.

2. Case presentation: opening clinical assessment, history of treatment and summary of patient characteristics from the presenting clinician. At the conclusion of this step specific issues might or might not be tabled.

3. Provision of additional information: descriptions/interpretations from the pathologist, or radiologist, or others who had been involved in particular diagnostic activities, where relevant. 4. Discussion: where any others attending could comment on the background information or diagnostic findings presented, seek clarification, offer advice or additional information. 5. Articulation of treatment plan: an existing or proposed course of action was agreed on, sometimes implicitly, something that has been noted in other health team research (Opie, 2000). The plan can be to wait or to do nothing. Explicit assent to the plan was rarely requested. 6. 'Preclosure': a move to terminate the discussion of the case.

7. 'Closure': when someone, sometimes the chairperson, sometimes another member, successfully directed attention to the next patient. 
Within this basic structure there was often some variation. Steps 3-5 in particular sometimes occurred in a different sequence, or could be truncated or omitted altogether. This was likely to occur in situations when the case was on the list for a specific issue. For example, in one case chest diagnostic tests of a patient had been requested and they had come to the meeting for review. The tests were all clear so there was little discussion and the time spent on this case was 90 seconds. Additional components were also observed in some cases. These included 'educational' components such as the pathologist explaining the function of certain cells, and 'side sequence' discussions about a range of issues including the value of particular

procedures, the outcome from particular treatments, or the changing nature of investigative and treatment procedures.

\section{Specific Agendas}

There was variation between MDMs and within MDMs regarding the degree to which the reason for presenting the case was made explicit and/or a specific problem or question was tabled by the presenting clinician. However, for each case discussion that proceeded beyond the initial opening, it was possible to identify one or more of the following specific reasons for presenting the case:

- Sharing of information, where all decisions had been made prior to the meeting (e.g., describing the site of the breast cancer, lymph node infiltration, surgical treatment to date, pathology reports on the cancer and current chemotherapy).

- Justifying actions taken to date. This is distinguished from the former in that it arises in situations where some action might be contestable, and the presenter justified the variation from the norm (e.g., a patient not having surgery to remove a tumour when that would be the usual clinical plan). 
- Reviewing tests ordered previously (e.g., "so the question really is what does the histology show and what's worth biopsying next").

- Clarifying a diagnosis or assessment (e.g., "I wondered, is it really dysplasia, or is it a post-inflammatory change?").

- Procedural follow up such as a referral or investigation.

- Determining appropriateness of a course of action (e.g., in situations where there might be different reasonable options or sets of options which are presented for discussion).

- Asking for suggestions about how to proceed (e.g., a surgeon stated "I suspect it's a lung primary, and the question is, are we going to do anything? Because I get the impression from cardiothoracics that they're not.”)

In almost all cases if there were different options the possible treatment plans were very clear. It was rare for there to be a high level of uncertainty about how to proceed. There was one case in the dataset where the presenting clinician was at a loss stating "I must admit I'm not sure where you go really."

\section{Authority within MDMs}

There were different forms and sources of authority in the MDMs analyzed. Authority could be seen in the role of the chairperson, bringing discussions to a close, and in some members speaking more frequently or at greater length than others. In terms of the organization of turn taking in the MDMs there was mostly self-selection of speakers in discussion sections (Elements 3 and 4 primarily). At other points there seemed to be an implicit understanding of whose role it was to comment (e.g., presenting physician, pathologist commenting on slides). Almost all the talking was done by senior clinicians with registrars (known as residents in the United States) 
taking a more prominent role only when presenting a case. There was considerably less input from nurses and others present.

Actions and planned actions were legitimated in a variety of ways and were based on different types of 'knowledge'. The following sources of authority were identified in the data. Encountered authority. This is an authority that is accorded to the clinician who has encountered the patient. In general, an assessment made by the clinician who has met the patient carried a great deal of weight in decision making discussions, although there were exceptions to this. Encountered authority particularly came into play when there were different treatment pathways being considered. To illustrate, in one meeting a case was discussed of a rectal cancer patient with a pacemaker. It was noted that this was "a pretty high risk situation for surgery" but the presenting surgeon had met the patient and determined that "he actually works reasonably well" so, on the basis of an in-person assessment of the general fitness of the patient the decision was “straight to surgery." As noted, cancer care MDMs differ from many multidisciplinary team meetings in the likelihood of participants in the meeting having met the patient being discussed. In palliative, disability, elderly and nursing home care MDMs many team members might have met the patient, and what can then be salient is the different accounts of the patient and whose account prevails (Gubrium, 1980; Opie, 2000; Wittenberg-Lyles, Parker Oliver, Demiris, \& Regehr, 2010).

Technological authority. Authority often resided in the 'presented' evidence in the form of pathology/histology reports and various scans. This technological authority can be crucially important. In one case there was a discrepancy between CT and cytology which made confirmation of the diagnosis uncertain and without such confirmation it was likely to be 
difficult to get the preferred treatment option reimbursed, so funding was dependent on the findings.

Authority from research evidence. At times scientific or research-based evidence was used as an explicit authority although this was quite rare. It was noted when there was a lack of certainty in relation to a case. One rare example of a discussion occurred when a particular option was proposed and one team member stated "half of the recurrences in a large population base study in Stockholm are from high rectal cancers" and went on to say that the researchers did not recommend the procedure being discussed.

The authority of lived experience. Occasionally surgeons would note the actual physical feel and 'experience' of a particular patient as evidence for decision making. For example, one surgeon noted that a patient had "the most horrible tissue" and because of this a conservative approach was taken to surgery. The decision was not to support radiotherapy on 'clinical' grounds in relation to the poor "vascularization of the tissue," even though another surgeon present appeared to contest this saying "you can see the blood vessels going through the breast. So they are there." In this instance the experiential authority of 'horrible tissue' trumped the technological authority of the image.

The authority of clinical experience. Clinicians can also support a case on the basis of personal experience with this type of condition and their views on how patients like this will respond. Authority of the interpreter. Authority can reside in the person interpreting the images in cases where there is some doubt. In one meeting the view was expressed that, in relation to the images being viewed, "the key thing is really that . . whoever's reviewing it says this is good quality." So for example, if the view is expressed that the image is good enough, additional testing would not be required in determining the course of action. 
Authority of the referral. Where there is no encountered authority the authority of the referral letter becomes important, but in some cases this source of authority posed difficulties for the MDM. For example, in one MDM where a case was referred from another centre questions were asked that could not be answered: "Do you know why they did an RFA (radiofrequency ablation) and not surgery?" with the response "Doesn't say in the letter." In addition a "CT" was taken at another hospital but "it isn't in our system." The decision was to wait until the scans were received - so the technological authority was to be called on when the referral letter was not specific enough.

In many cases the sources of authority were mutually reinforcing in terms of decision making. They built on each other leading to an agreed conclusion. For example, in one case the patient's age was made relevant as part of the decision making not to go to additional surgery, but more was made of the type of cancer. The authority of research (patients of this age do not do well) and of personal clinical experience (patients like this I have worked on in the past do not do well) was combined with a technological authority (the identification of the particular type of cancer via technological investigations) to support the decision.

There were cases where the sources of authority were in conflict. When this occurred there was no one source of authority that had the 'final' say in every case, but personal clinical experience and having encountered the patient were particularly important as in the case of the rectal cancer patient noted above.

Justifying Actions and Strategies of Persuasion

Meeting members drew on a number of strategies in attempts to persuade other members to their point of view. Variations in the way in which cases were presented alerted us to these justifying actions. At times the treatment pathway preferred was not what might have been expected. In 
cases like this the presenting clinician might counter potential opposition by means of particular interactional strategies and/or justifications. Justifications included claiming clinical and experiential authority.

A common example of an interactional strategy was overtalk, where participants attempted to gain the floor, or speaking rights, prior to the end of someone else's turn of talk. Overtalk could be used to reject the value position taken by another MDM member, for example where a member used overtalk that emphasized their encountered authority and so interrupted another MDM member who was emphasising a patient empowerment approach (see next section for additional illustration).

Membership categorization devices, outlined above, were also used. For example, in one MDM the occupation of the patient was made relevant, and she was described as a 'colour therapist'. The presenting clinician stated that "my guess is that she will decline the offer of surgery." The occupational category here implicitly links to category bound activities like pursing alternative treatments. Making occupation relevant thus supported the clinician's 'guess' that she might decline the suggested intervention.

Physical state categorizations imply the capacity to undertake activities or the capacity to respond to treatment options. The term "category bound capacities," which relates particular abilities to particular categories, aptly describes the associations implied when physical state categories are invoked. The categorization of a patient as 'very frail', corroborated by information that she was booked for a colonoscopy but was turned away because of her condition, supported a decision not to intervene at this stage. The categorization of someone as working "reasonably well," as noted above, supported a decision to go to surgery. 
In the entire data set ethnicity as a category was explicitly stated on only three occasions, and each was a different ethnicity (Chinese, Samoan, and Māori). In two of the three cases the particular descriptors associated with ethnicity could be interpreted as having moral overtones. The patient noted as Samoan was described as "morbidly obese... 165 kilos of Samoan, most of which is blubber, some of which is muscle." The Māori patient was described as "a chainsmoking Māori lady." The descriptors for the Chinese patient appear neutral: "an 88-year old Chinese lady."

There was no clear relationship between these categorizations of ethnicity and subsequent discussion. For the Samoan patient the team was waiting on a histology report to confirm the diagnosis, for the Māori 'lady' the team was waiting for a report from a neurosurgeon before deciding whether to operate, and for the Chinese 'lady' a decision was made to undertake an operation. In all the other cases ethnicity was not mentioned, although there was some diversity in the sample, with for example 10 of the 106 cases identified as Māori in the medical records.

Extreme case formulations are expressions using very strong or exaggerated terms and were observed to be used to build support for a course of action that the clinician preferred, particularly evident in situations where the course of action might be open to contest. The example of "most horrible tissue" noted above illustrates this. Extreme case formulation could cross over into clinical terminology. In one MDM there was a discussion about whether the term "severe high grade dysplasia" was technical or not. The word "severe" is an example of an extreme case formulation. In the MDM this phrase was described as a tautology, because it was clinically redundant, but it served an interactional purpose because it allowed the clinician to suggest something was "more suspicious there."

Identifiable Value Positions 
A number of distinctly different value positions could be identified in the discussions. The broad typology outlined below should not be considered simply as a set of internalized enduring norms. Rather they were used as rhetorical strategies that were displayed in particular discussions to achieve particular goals.

Utilitarian. Where interventions are seen in relation to the patient population. The focus was on the efficient use of resources to maximize benefits. So for example, in one case it was argued that even if patients might find a PET scan helps relieve their anxiety, if those scans have no bearing on clinical management they should not be used. The rationale being that the resource is scarce and should be reserved for when it was most needed.

Paternalistic Pastoralism. Where interventions are seen in relation to the particular patient and what might be achieved for that person - the patient might not be the right person to make that decision, rather it is the clinician. From this position it might be seen as appropriate not to divulge all information to the patient because it might make the situation worse. Outcomes are focused on the good of the particular patient.

Beneficent Pastoralism. Where an overriding concern is to support the wellbeing of the patient. This might involve using interventions that have no impact on clinical management and come at a cost to the health system, such as the PET scans mentioned above, but which have the potential to enhance the wellbeing of the patient.

Patient-empowerment. Where interventions are to be decided by the patient in discussion with the clinician. The patient should have all information to hand, and whether that is good for their 'wellbeing' is not to be determined by the clinician taking a pastoral care role.

Procedural. Where interventions are based on protocols and processes that have been established. The particular situation of the patient and the views of the clinicians take a secondary place. For 
example, when it was noted by a meeting member that there was an increasing tendency to have particular diagnostic procedures undertaken because they were "new and sexy" it was suggested that this tendency could be resisted by following relevant referral criteria.

Clinician self-preservation. Where interventions are based on the clinician's responses to the patient or characteristics of the patient in relation to clinical issues. For example, in one case a patient was seen as 'prickly' and this limited the sort of interaction the clinician wanted to have with the patient.

Within some MDM discussions it was evident that different participants held different value positions. In one case the patient was 81 and with her condition there was a view expressed that she would die of something else first even if there was cancer. A clinician had told the patient that her biopsies "showed no cancer" even though this was "not all true." He justified this by saying "I don't think she has got the capacity to understand and be happy with the uncertainty ... let's protect her." The clinician's view was contested by a breast care nurse saying "ask the patient what she thinks." Here a paternalistic pastoral position conflicted with a patientempowerment position.

\section{Decisions by Distance}

As noted previously, it appeared to be a disadvantage if patients had not been seen by one of the team members, which meant that no team member could exercise encountered authority. This made it difficult for the MDM to assess patient factors that might influence decisions. In one MDM there was difficulty in dealing with a complex case primarily overseen by another team. The MDM was unclear about the best decision so the team drew on the technological authority of the scans, the evidence of clinical reports and other information about the patient's condition. In another case the patient was from a provincial hospital at some distance from the centre. 
When discussing the referral letter it was stated that "reading between the lines of the letter I think it's - her treatment is probably palliative, but I thought I'd review the films." After describing the clinical history, including having liver metastases, one member noted that there were "significant um constitutional symptoms" and a "loss of fitness over the course of all this." The decision was made with "I think they just needed a letter saying that she'll not proceed." In this case the team undertook interpretive work to determine what was wanted from those making the referral.

In another case of a referral from a provincial hospital the team identified the issue as "I think he just wondered if there was a surgical option for her." The anatomical issues were described and there was some confusion about what had been done: "I don't quite understand what they were doing," and questions were raised, for example, "why is there an anastomosis?" which was responded to with "I don't know why that is." In this we see a lack of clarity about why some things have been done to this patient and what is being requested, and no one present in the room could answer these questions because of incomplete information. The decision was then "Okay, I'll see what they want doing."

Another form of distance is when there is no encountered authority because the clinician overseeing the case is not present at the meeting. In one case a number of questions were asked that were not answered, at least in part because the surgeon was not present and therefore the MDM did not have the context for why decisions were made. Questions raised included "did we understage this" and "why did we not go on" and members expressed surprise that a referral to medical oncology had not happened earlier.

Finally, there can be distance in relation to time. In one case a question was clearly stated "are we still looking at chemotherapy or are we going to try to put a palliative stent in" because 
the patient has "brain mets." The impact of these on her functioning was not known as the presenting surgeon has not seen her for five weeks. A decision was made to "stent" her based on the pathology reports which appeared to be clear enough to override any concerns about a lack of any recent encounter and in-person assessment of the case.

\section{Possible Missed Potential for Learning and Systemic Improvement}

There were a number of examples where there had been some event of significance noted but this did not get explored in more detaail in the MDM. In one case it was expressed that "we just grossly underestimated the amount of disease she had." There was no explicit statement in relation to following up on the process of "underestimation" to determine if something could have been done differently. In a similar case the surgeon was not present but questions were raised about the possible understaging of disease and delay to surgery. In the actual meeting there was no explicitly stated decision to follow this up and find out what happened.

\section{Discussion}

Through an examination of what is said in cancer care MDMs and how issues are discussed we have described the typical process, identified important sources of authority used in these MDMs, identified value positions taken by members and described some of the interactional and rhetorical strategies used to persuade members to follow particular courses of action.

A limitation of our analysis is that it relies solely on audio data because we did not have access to documents and images used in the meetings. We undertook audio recordings overtly so

all team members were aware that they were being recorded. Despite this the recordings identify robust discussion and many features of MDMs not previously noted. The dataset of 106 patientdiscussions, although allowing an identification of processes, positions of authority and values, limits identifying patterns that might apply to different social and ethnic groupings. Additionally, 
MDMs are only one step in the decision making process so they are only one influence on treatment plans.

Our goal in this research was to try to identify aspects of health care delivery that would lead to unequal outcomes for different ethnic groups. To deal with the complexity of our daily lives we all categorize (van Ryn \& Burke, 2000). We have shown that some categories are rarely used, and that when they are used they are often doing some work in justifying suggestions. In particular, categorizations related to perceived character traits, to occupation and to the assessed physical capacity of the patients under discussion can be consequential. It is unclear in this data whether and how ethnicity is consequential as, in those rare cases where it was made relevant, we were not able to discern whether and how it was used in supporting suggested plans of action. However, when these rare categorizations are made relevant, team members can be alerted to the kind of work that this might be doing, and as suggested in the literature, reflecting on these characterizations can foster different thinking (Arber \& Gallagher, 2009; Opie, 2000),

Whether the patient is known by one or more MDM members is an important issue in terms of considering patient preferences (Lanceley et al., 2008). The research we have discussed here supports this and we identify a number of other elements in relation to knowing the patient - such as an assessment of patient wellbeing. Given the importance of encountered authority, MDMs are at a disadvantage when discussion relates to a case where no one present has interacted with the patient. MDMs then have difficulty in determining what issues are most salient and what the course of action should be - and sometimes even a lack of clarity over why the case was being presented.

In an Australian study it was found that newly diagnosed lung cancer patients who do not speak English are less likely to receive anticancer treatment than those patients who do speak 
English (Vinod, Sidhom, Gabriel, Lee, \& Delaney, 2010). This again suggests an issue of 'distance', this time sociocultural and/or communicative distance, impacting on clinical decision making. Physician decision (as opposed to technical factors, comorbidities or patient decision) can be the major reason for not following recommended guidelines in relation to lung cancer treatments (Vinod, Sidhom, \& Delaney, 2010). If this finding is generalizable to other settings then this suggests the crucial role of the individual physician and his or her assessment of relevant patient characteristics.

Given the importance of encountered authority there is potential for patients who have not been seen by someone at the MDM to be at a disadvantage. Videoconferencing might help address this concern. Its use to enhance the communication between community based surgeons and cancer centres has been supported by research on surgeons' views (Gagliardi, Wright, Davis, McLeod, \& Urbach, 2008). Videoconferencing used by some cancer teams in the United Kingdom improved meeting attendance and did not negatively affect care. One drawback is that the technology can also slow down the meeting and therefore the number of cases discussed (Lamb, Brown, et al., 2011).

The findings of our research have a number of important implications for the running of MDMs in terms of ensuring that outcomes are fair for all social groups. First, the role of the chairperson and the capacity of the MDMs to observe and reflect on their own processes are central. This aligns with Opie's argument that teams should focus on their processes of knowledge production if they are to be effective, to foster an awareness of comments that have not been followed up on or that go unnoticed, and to explore different accounts instead of overlooking or suppressing them (Opie, 2000). It also aligns with Crepeau's argument that teams should be aware of the moral components of patient discussions and how they can impact on 
clinical decision making (Crepeau, 2000). It is possible that implicit assumptions about whose role it is to talk affects the relative lack of contribution observed from some team members, such as nurses and registrars. Nurses and junior team members rarely overtly contribute to discussions (Lamb, Brown, et al., 2011). To change this directed efforts at achieving their input is required.

Second, MDM members hold different value positions that could influence their preferences. Where identifiable issues arise, chairpersons could ensure that different views are expressed so that consensus value positions are made clear. Finally, MDM members draw on different sources of authority. Awareness of this will enhance the identification of what authority is being drawn on in any particular discussion and provide opportunities for drawing in other sources where relevant. MDMs could consider processes whereby 'resistance' to decisions by colleagues becomes seen as an opportunity to reach a greater understanding of the issue. In some MDMs resistance or alternative views can be quickly closed down and it is not clear why suggestions have not been followed up. Chairpersons could note when suggestions for alternative plans are being made and explicitly respond to those suggestions. In addition, where the chairperson is not presenting a case different viewpoints are more likely to be canvassed. If the chairperson presents a case chairing duties could be explicitly handed over to another team member.

Future research covering a broader range of MDMs in different settings and jurisdictions would very likely uncover additional sources of authority, value positions, categorizations made relevant and strategies used, which could provide more information to identify aspects of MDMs that promote differential treatment of social groups. Given the importance of encountered authority, future research could identify if there are differences in the frequency of encountered authority by social group and ethnicity. Attending to issues of process, categorizations, authority 
and values in MDMs has the potential to improve cancer care decision making and ultimately health outcomes.

\section{Declaration of Conflicts of Interest}

The authors declared no potential conflicts of interest with respect to the research, authorship, and publication of this article.

\section{Funding}

The authors disclosed receipt of the following financial support for the research: the Health Research Council of New Zealand (Grant 11/202) 


\section{References}

Arber, A. (2007). "Pain talk" in hospice and palliative care meetings: An ethnography. International Journal of Nursing Studies, 44, 916-926. doi: http://dx.doi.org/10.1016/j.ijnurstu.2006.04.002

Arber, A. (2008). Team meetings in specialist palliative care: Asking questions as a strategy within interprofessional interaction. Qualitative Health Research, 18(10), 1323-1335. doi: $10.1177 / 1049732308322588$

Arber, A., \& Gallagher, A. (2009). Generosity and the moral imagination in the practice of teamwork. Nursing Ethics, 16(6), 775-785. doi:10.1177/0969733009343134

Cormack, D., Ratima, M., Robson, B., Brown, R., \& Purdie, G. (2005). Access to Cancer Services for Māori. Wellington. URL:

http://www.health.govt.nz/system/files/documents/publications/maoricancerserviceaccess .pdf

Crepeau, E. (2000). Reconstructiong Gloria: A narrative analysis of team meetings. Qualitative Health Research, 10(6), 766-787. doi:10.1177/104973200129118813

Demiris, G., Washington, K., Parker Oliver, D., \& Wittenberg-Lyles, E. (2008). A study of information flow in hospice interddisciplinary team meetings. Journal of Interprofessional Care, 22(6), 621-629. doi:10.1080/13561820802380027

Fleissig, A., Jenkins, V., Catt, S., \& Fallowfield, L. (2006). Multidisciplinary teams in cancer care: are they effective in the UK? Lancet Oncology, 7(11), 935-943. doi:

10.1016/S1470-2045(06)70940-8 
Gagliardi, A., Wright, F., Davis, D., McLeod, R., \& Urbach, D. (2008). Challenges in multidisciplinary cancer care among general surgeons in Canada. BMC Medical Informatics and Decision Making, 9(59), 1-10. doi:10.1186/1472-6947-8-59

Gubrium, J. (1980). Doing care plans in patient conferences. Social Science and Medicine, 14A(6), 659-667. doi: 10.1016/S0271-7123(80)80076-9

Haward, R., Amir, Z., Borrill, C., Dawson, J., Scully, J., West, M., \& Sainsbury, R. (2003). Breast cancer teams: the impact of constitution, new cancer workload, and methods of operation on their effectiveness. British Journal of Cancer, 89(1), 15-22. doi: 10.1038/sj.bjc.6601073

Heritage, J., \& Maynard, D. W. (Eds.). (2006). Communication in medical care: interaction between primary care physicians and patients. Cambridge: Cambridge University Press.

Hill, S., Sarfati, D., Blakely, T., Robson, B., Purdie, G., Chen, J., . . Kawachi, I. (2010). Survival disparities in Indigenous and non-Indigenous New Zealanders with colon cancer: the role of patient comorbidity, treatment and health service factors. Journal of Epidemiology and Community Health, 64(2), 117-123. doi: 10.1136/jech.2008.083816

Hill, S., Sarfati, D., Blakely, T., Robson, B., Purdie, G., Dennett, E., . . Kawachi, I. (2010). Ethnicity and Management of Colon Cancer in New Zealand. Do Indigenous Patients Get a Worse Deal? Cancer, 116(13), 3205-3214. doi: 10.1002/cncr.25127

Kidger, J., Murdoch, J., Donovan, J. L., \& Blazeby, J. M. (2009). Clinical decision-making in a multidisciplinary gynaecological cancer team: A qualitative study. BJOG: An International Journal of Obstetrics and Gynaecology, 116(4), 511-517. doi: 10.1111/j.1471-0528.2008.02066.x 
Lamb, B., Brown, K., Nagpal, K., Vincent, C., \& Green, J. (2011). Quality of Care Management Decisions by Multidisciplinary Cancer Teams: A Systematic Review. Annals of Surgical Oncology, 18(8), 2116-2125. doi: 10.1245/s10434-011-1675-6

Lamb, B., Sevdalis, N., Mostafid, H., Vincent, C., \& Green, J. (2011). Quality Improvment in Multidisciplinary Cancer Teams: An Investigation of Teamwork and Clinical DecisionMaking and Cross-Validation of Assessments. Annals of Surgical Oncology, 18(13), 3535-3543. doi: 10.1245/s10434-011-1773-5

Lanceley, A., Savage, J., Menon, U., \& Jacobs, I. (2008). Influences on multidisciplinary team decision-making. International Journal of Gynecological Cancer, 18(2), 215-222. doi: 10.1111/j.1525-1438.2007.00991.x

Lepper, G. (2000). Categories in text and talk: A practical introduction to categorization analysis. London: Sage.

National Institute for Health and Clinical Excellence. (2006). Guidance on cancer services: improving outcomes for people with brain and other CNS tumours. London: National Institute for Health and Clinical Excellence. http://www.nice.org.uk/nicemedia/pdf/CSG_brain_manual.pdf

National Institute for Health and Clinical Excellence. (2008). Prostate cancer: Diagnosis and treatment. London: National Institute for Health and Clinical Excellence. http://www.nice.org.uk/nicemedia/pdf/CG58FullGuideline.pdf

New Zealand Guidelines Group. (2011). Management of Early Colorectal Cancer: Evidencebased guideline. Wellington: New Zealand Guidelines Group. http://www.health.govt.nz/system/files/documents/publications/early-managementcolorectal-cancer-guideline.pdf 
Opie, A. (2000). Thinking teams/thinking clients: Knowledge-based teamwork. New York: Columbia University Press.

Patkar, V., Acosta, D., Davidson, T., Jones, A., Fox, J., \& Keshtgar, M. (2011). Cancer Multidisciplinary Team Meetings: Evidence, Challenges, and the Role of Clinical Decision Support Technology. International Journal of Breast Cancer, 2011, 1-7. doi: $10.4061 / 2011 / 831605$

Prades, J., \& Borras, J. M. (2011). Multidisciplinary cancer care in Spain, or when the function creates the organ: qualitative interview study. BMC Public Health, 11. doi: 141 $10.1186 / 1471-2458-11-141$

Saini, K. S., Taylor, C., Ramirez, A.-J., Palmieri, C., Gunnarsson, U., Schmoll, H. J., . . . de Azambuja, E. (2012). Role of the multidisciplinary team in breast cancer management: results from a large international survey involving 39 countries. Annals of Oncology, 23(4), 853-859. doi: 10.1093/annonc/mdr352

Stivers, T. (2006). Treatment decisions: negotiations between doctors and parents in acute care encounters. In J. Heritage \& D. W. Maynard (Eds.), Communication in Medical Care: interaction between primary care physicians and patients (pp. 279-312). Cambridge: Cambridge University Press.

Stokoe, E. (2012). Moving forward with membership categorization analysis: Methods for systematic analysis. Discourse Studies, 14(3), 277-303. doi: 10.1177/1461445612441534

Taylor, C., Munro, A. J., Glynne-Jones, R., Griffith, C., Trevatt, P., Richards, M., \& Ramirez, A. J. (2010). Multidisciplinary team working in cancer: what is the evidence? British Medical Journal, 340. doi: c95110.1136/bmj.c951

ten Have, P. (1999). Doing Conversation Analysis: A Practical Guide. 
ten Have, P. (2004). Understanding qualitative research and ethnomethodology. London: Sage. van Ryn, M., \& Burke, J. (2000). The effect of patient race and socio-economic status on physician's perceptions of patients. Social Science \& Medicine, 50, 813-828. doi.org/10.1016/S0277-9536(99)00338-X

Vinod, S., Sidhom, M., \& Delaney, G. (2010). Do multidisciplinary meetings follow guildlinebased care? Journal of Oncology Practice, 6(6), 276-281. doi: 10.1200/JOP.2010.000019

Vinod, S., Sidhom, M., Gabriel, G., Lee, M., \& Delaney, G. (2010). Why do some lung cancer patients receive no anticancer treatment? Journal of Thoracic Oncology, 5(7), 1025-1032. doi: 10.1097/JTO.0b013e3181da85e4

White, S. (2002). Accomplishing 'the case' in paediatrics and child health: Medicine and moarlity in inter-professional talk. Sociology of Health and Illness, 24(4), 409-435. doi: $10.1111 / 1467-9566.00302$

Wittenberg-Lyles, E. (2005). Information sharing in interdisciplinary team meetings: An evaluation of hospice goals. Qualitative Health Research, 15(10), 1377-1391. doi:10.1177/1049732305282857

Wittenberg-Lyles, E., Parker Oliver, D., Demiris, G., \& Regehr, K. (2010). Interdisciplinary collaboration in hospice team meetings. Journal of Interprofessional Care, 24(3), 264273. doi: $10.3109 / 13561820903163421$

\section{Bios}

Kevin Dew, $\mathrm{PhD}$, is a Professor of Sociology in the Victoria University of Wellington Sociology and Social Policy Programme, Wellington, New Zealand. 
Maria Stubbe, $\mathrm{PhD}$, is a senior lecturer in the Department of Primary Care and General Practice, Wellington School of Medicine and Health Sciences, University of Otago, New Zealand.

Louise Signal, $\mathrm{PhD}$, is an associate professor in the Cancer Control and Screening Research Group, University of Otago, New Zealand.

Jeannine Stairmand, DPH, is an assistant research fellow with the Cancer Control and Screening Research Group, University of Otago, New Zealand.

Elizabeth Dennett, MBChB, MMed.Sci and FRACS, is a research clinician at the, Department of Surgery and Anaesthesia, Wellington School of Medicine and Health Sciences, University of Otago, New Zealand.

Jonathan Koea, MBChB, FACS and FACS, is a research clinician at the Department of Surgery, North Shore Hospital, Auckland 0632, New Zealand.

Andrew Simpson, MBChB and FRACS, is a research clinician at the Blood and Cancer Centre, Wellington Hospital, Wellington, New Zealand.

Diana Sarfati, MBChB and MPH, is an associate professor, Cancer Control and Screening Research Group, University of Otago, New Zealand.

Chris Cunningham, $\mathrm{PhD}$, is a professor at the Research Centre for Māori Health and Development, Massey University, New Zealand.

Lesley Batten, $\mathrm{PhD}$, is a senior research officer at the Research Centre for Māori Health and Development, Massey University, New Zealand. 
Lis Ellison-Loschmann, PhD, is a senior research officer, Centre for Public Health Research, Massey University, New Zealand.

Josh Barton, MA, is a PhD student with the Sociology and Social Policy Programme, Victoria University of Wellington, New Zealand.

Maureen Holdaway, $\mathrm{PhD}$, is an associate director at Te Pūmanawa Hauora, Massey University, New Zealand. 